\title{
Pengaruh Media Pembelajaran Matematika dengan Menggunakan Permainan Ular Tangga berbasis Budaya Banten dan Motivasi Belajar terhadap Kemampuan Pemecahan Masalah Matematik Siswa SD Kelas IV
}

\author{
Suparji Rustam, Ajat Sudrajat dan Supriadi \\ Universitas Terbuka, Indonesia \\ Email korepondensi: suparjirustam@gmail.com
}

\begin{abstract}
ABSTRAK
Penelitian ini dilatarbelakangi rendahnya kemampuan pemecahan masalah matematik siswa SD kelas IV dan masih terdapat siswa yang belum mengetahui kebudayaan Banten serta motvasi belajar yang rendah dalam proses pembelajaran. Media pembelajaran permainan ular tangga berbasis budaya Banten dapat mengarahkan siswa untuk lebih aktif dan meningkatkan kemampuan pemecahan masalah matematik dalam proses pembelajaran. Populasi dalam penelitian ini adalah seluruh siswa SD Kelas IV di SD Negeri Rancabango III Kecamatan Rajeg Kabupaten Tangerang tahun pelajaran 2020/2021 dan teknik pengambilan sample dalam penelitian ini dilakukan secara random sampling sehingga diperoleh dua kelompok yaitu kelompok eksperimen dan kelompok kontrol. Kedua kelompok tersebut diberikan perlakuan yag berbeda. Penelitian ini bertujuan untuk mengetahui : 1) Untuk mengetahui kemampuan pemecahan masalah matematik antara siswa yang menggunakan media pembelajaran permainan ular tangga berbasis budaya Banten lebih unggul dari pada siswa yang menggunakan pembelajaran ekspositori; 2) untuk mengetahui pengaruh interaksi antara media pembelajaran permainan ular tangga berbasis budaya Banten dan motivasi belajar terhadap kemampuan matematik siswa SD kelas IV. Hasil penelitian menunjukkan : 1) Kemampuan pemecahan masalah matematik siswa yang menggunakan media pembelajaran permainan ular tangga berbasis budaya Banten lebih unggul dari pada kemampuan pemecahan masalah matematik siswa yang menggunakan pembelajaran ekspositori, 2) terdapat pengaruh interaksi antara pembelajaran dan motivasi belajar terhadap kemampuan matematik siswa kelas IV SD.
\end{abstract}

Kata Kunci: Media Pembelajaan, Permainan Ular Tangga, Budaya Banten, Motivasi, Pemecahan Masalah Matematik

\section{ABSTRACT}

This research is motivated by the low mathematical problem-solving ability of elementary school students in grade IV, and there are still students who do not know Banten culture and low learning motivation in the learning process. The learning media for the game of snakes and ladders based on Banten culture can lead students to be more active and improve their mathematical problem-solving skills in the learning process. The population in this study were all fourth-grade elementary school students at Rancepato III Public Elementary School, Rajeg District, Tangerang Regency, for the 2020/2021 academic year, and the sampling technique in this study was carried out by random sampling so that two groups were obtained, namely the experimental group and the control group. The two groups were given different treatments. This study aims to determine: 1) To determine the mathematical problem-solving ability of students who use learning media of snake and ladder game based on Banten culture is superior to students who use expository learning; 2) to determine the effect of the interaction between the learning media of the game of snakes and ladders based on Banten culture and learning 
motivation on the mathematical abilities of fourth-grade elementary school students. The results showed: 1) The mathematical problem-solving ability of students who used the snake and ladder game learning media based on Banten culture was superior to the mathematical problem-solving abilities of students who used expository learning, 2) there was an interaction effect between learning and learning motivation on the mathematical abilities of class students grade $I V$.

Keyword: Learning Media, Snakes and Ladders Game, Banten Culture, Motivation, Mathematical Problem Solving

\section{PENDAHULUAN}

Media pembelajaran merupakan sarana yang menjadi salah satu penunjang dalam proses belajar mengajar. Berbagai macam media pembelajaran selain sebagai alat penunjang, juga menjadi faktor dalam keberhasilan dalam proses pembelajaran. Saat ini telah banyak berkembang dan berinovasi dalam dunia pendidikan, mulai dari buku sampai media elektronik. Penggunaan media dalam proses pembelajaran tidak berdiri dengan sendirinya melainkan saling berhubungan dengan komponen lain agar proses pembelajaran berjalan dengan apa yang diharapkan.

Mata pelajaran matematika merupakan salah satu pelajaran yang dianggap sulit bagi siswa, apalagi bila diaplikasikan dalam kehidupan nyata, maka perlu dikaitkan dengan situasi kehidupan sehari-hari siswa. Data hasil ulangan harian siswa pada mata pelajaran matematika materi kelipatan dan faktor suatu bilangan menunjukan masih banyak siswa yang belum mencapai ketuntasan belajar minimal (KBM) yang ditetapkan untuk mata pelajaran tersebut. Terdapat $60 \%$ siswa dari 40 siswa jumlah keseluruhan masih belum mencapai KBM. Itu berarti ada 24 orang siswa yang mendapatkan nilai dibawah KBM dengan nilai batas minimal 68 . Berdasarkan hasil observasi diperoleh beberapa gambaran mengenai proses belajar mengajar dan kondisi peserta didik dalam evaluasi pembelajaran mata pelajaran matematika. Terdapat beberapa permasalahan yang ditemukan saat kegiatan belajar mengajar pada kelipatan dan faktor suatu bilangan. Siswa mengalami kesulitan ketika dilaksanakan evaluasi (tes), hal tersebut tampak pada kesalahan siswa mengerjakan soal kelipatan bilangan dan faktor bilangan pada soal cerita. Permasalahan lain yang muncul yaitu siswa kurang termotivasi dan masih kesulitan dalam menggunakan, menafsirkan dan melihat prosedur sehingga sebagian besar siswa memberikan jawaban salah ketika menyelesaikan soal berbeda dari contoh yang diberikan guru. Menurut Permatasari (2014), permainan ular tangga pun memiliki beberapa fungsi yang memberikan kebebasan kepada setiap peserta didik untuk berbicara baik di dalam kelas ataupun di luar kelas, sehingga peserta didik dapat melakukan interaksi belajar dengan lebih bebas/leluasa.

Penelitian yang akan dilakukan pada kesempatan ini, peneliti menggunakan media pembelajaran berupa permainan ular tangga dengan ukuran $3 \mathrm{~m} \times 3 \mathrm{~m}$ yang terbuat dari bahan banner/baliho, dengan ukuran tersebut para peserta didik dapat menggunakannya lebih jelas terlihat dan setiap peserta didik yang ikut dalam permainan tersebut dapat berdiri secara leluasa di setiap kotaknya. Dalam setiap kotak yang terdapat dalam media tersebut bercorak atau bergambar kebudayaan Banten, yang tersebar di 8 Kabupaten/Kota di Provinsi Banten.

Berdasarkan dari latar belakang di atas, maka penulis merumuskan permasalahan dalam penelitian ini ialah :

1. Apakah kemampuan pemecahan masalah matematik antara siswa yang menggunakan media pembelajaran permainan ular tangga berbasis budaya Banten lebih unggul dari pada siswa yang menggunakan pembelajaran ekspositori? 
2. Apakah terdapat interaksi antara media pembelajaran permainan ular tangga berbasis budaya Banten dan motivasi belajar terhadap kemampuan pemecahan masalah matematik siswa SD kelas IV ?

Sesuai dengan rumusan masalah yang telah dirumuskan diatas maka tujuan yang hendak dicapai dalam penelitian ini adalah :

1. Untuk mengetahui kemampuan pemecahan masalah matematik antara siswa yang menggunakan media pembelajaran permainan ular tangga berbasis budaya Banten lebih unggul dari pada siswa yang menggunakan pembelajaran ekspositori.

2. Untuk mengetahui pengaruh interaksi antara media pembelajaran permainan ular tangga berbasis budaya Banten dan motivasi belajar terhadap kemampuan matematik siswa SD kelas IV.

\section{METODE}

Pada penelitian ini, peneliti menggunakan desain penelitian Eksperimental Semu (QuasiExperimental Research) karena terdapat dua kelompok sampel yang akan diteliti, kelompok eksperimen dan kelompok kontrol. Desain yang digunakan dalam penelitian ini yaitu desain faktorial. Variabel independen yang dimaksud dalam penelitian ini yaitu media pembelajaran permainan ular tangga berbasis budaya Banten dan motivasi. jumlah sampel yang digunakan 10\% dari jumlah populasi sebanyak 411 siswa, maka sebanyak 40 (empat puluh) siswa kelas IV SDN Rancabango III Kecamatan Rajeg Kabupaten Tangerang, sesuai dengan jumlah siswa yang ada di kelas tersebut.

Dalam penelitian ini, instrumen penelitian yang digunakan untuk pengumpulan data adalah lembar pengamatan (guru dan siswa), angket, dan hasil evaluasi belajar siswa. Keempat instrumen tersebut dijabarkan sebagai berikut, diantaranya: 1) Test Kemampuan Pemecahan Masalah; 2) Instrumen Angket Motivasi Belajar Siswa. Data penelitian ini berupa data kualitatif yang digunakan untuk mengetahui kualitas media pembelajaran dengan kriteria: 1) tidak setuju, 2) kurang setuju, 3) setuju dan 4) sangat setuju. Sedangkan data kuantitatif diperoleh dengan memberikan skor pada kualitatif berdasarkan skala Likert yang dikoneversikan nilai skala 4 .

\section{HASIL DAN PEMBAHASAN}

Penelitian ini bertujuan untuk mengetahui pengaruh media pembelajaran matematika menggunakan permainan ular tangga berbasis budaya Banten terhadap kemampuan pemecahan masalah matematik siswa SD kelas IV. Kemampuan pemecahan masalah matematik dibagi ke dalam dua bagian. Pertama yaitu kemampuan pemecahan masalah matematik dengan menggunakan media pembelajaran permainan ular tangga berbasis budaya Banten, kemampuan pemecahan masalah matematik menggunakan media pembelajaran permainan ular tangga berbasis budaya Banten, diberikan pada siswa SD kelas IV sebagai kelas eksperimen dengan jumlah siswa 20 siswa, dengan jumlah Laki-laki : 10 siswa, Perempuan : 10 siswa. Semua siswa hadir dan telah melaksanakan pembelajaran dari awal sampai akhir.

Kedua, yaitu kemampuan pemecahan masalah matematik tanpa menggunakan media pembelajaran permainan ular tangga berbasis budaya Banten. Kemampuan pemecahan masalah matematik tanpa menggunakan media pembelajaran permainan ular tangga berbasis budaya Banten diberikan pada siswa SD kelasIV sebagai kelas kontrol dengan jumlah siswa 20 siswa, dengan jumlah Laki-laki : 10 siswa, Perempuan : 10 siswa, sama halnya dengan kelas eksperimen semua siswa hadir dan mengikuti pelajaran sampai selesai. Jadi, jumlah sampel secara keseluruhan adalah 40 . 
Data hasil penelitian diperoleh dari hasil angket motivasi belajar siswa dan tes kemampuan pemecahan masalah matematik. Data-data tersebut selanjutnya akan dilanalisis dengan menggunakan analis statistik menggunakan antuan software SPSS. Rangkaian hasil analisis data baik secara deskriptif ataupun inferensial disajikan sebagai berikut :

Tabel 1. Kalsifikasi Motivasi Belajar

\begin{tabular}{|c|c|c|c|}
\hline Eksperimen & Jumlah & Kontrol & Jumlah \\
\hline Tinggi & 8 & Tinggi & 6 \\
\hline Sedang & 7 & Sedang & 9 \\
\hline Rendah & 5 & Rendah & 5 \\
\hline
\end{tabular}

Deskripsi data kemampuan pemecahan masalah matematik siswa pada masing-masing kategori disajikan pada tabel berikut :

\section{Descriptive Statistics}

\begin{tabular}{|c|c|c|c|c|}
\hline \multicolumn{5}{|c|}{ Dependent Variable: Nilai } \\
\hline Motivasi & Kelas & Mean & Std. Deviation & $\mathrm{N}$ \\
\hline \multirow[t]{3}{*}{ Tinggi } & Eksperimen & 88,17 & 1,835 & 6 \\
\hline & Kontrol & 69,00 & 3,225 & 6 \\
\hline & Total & 78,58 & 10,317 & 12 \\
\hline \multirow[t]{3}{*}{ Sedang } & Eksperimen & 79,29 &, 951 & 7 \\
\hline & Kontrol & 69,00 & 5,292 & 9 \\
\hline & Total & 73,50 & 6,563 & 16 \\
\hline \multirow[t]{3}{*}{ Rendah } & Eksperimen & 70,00 &, 000 & 5 \\
\hline & Kontrol & 82,86 & 2,673 & 7 \\
\hline & Total & 77,50 & 6,908 & 12 \\
\hline \multirow[t]{3}{*}{ Total } & Eksperimen & 79,67 & 7,372 & 18 \\
\hline & Kontrol & 73,41 & 7,670 & 22 \\
\hline & Total & 76,23 & 8,081 & 40 \\
\hline
\end{tabular}

Dapat dilihat bahwa nilai rata-rata untuk kategori kemampuan matematik dengan media pembelajaran permainan ular tangga dan motivasi belajar tiggi yaitu sebesar 88,17, minat sedang sebasar 79,29 dan minat rendah 70,00. Sedangkan nilai rataan untuk kategori metode ekspositori minat tinggi yaitu sebesar 69,00, minat sedang 69,00 dan minat rendah sebasar 82,86 .

\section{Uji normalitas}

Perhitungan uji normalitas kelompok data kemampuan pemecahan masalah matematik dapat dilihat pada lampiran penelitian. Rangkuman hasil uji normalitas disajikan pada tabel berikut :

Hasil Uji Normalitas Data

Kemampuan Pemecahan Masalah Matematik

\begin{tabular}{|c|c|c|c|c|c|c|c|}
\hline \multicolumn{8}{|c|}{ Tests of Normality } \\
\hline & \multirow[t]{2}{*}{ Kelas } & \multicolumn{3}{|c|}{ Kolmogorov-Smirnov ${ }^{\mathrm{a}}$} & \multicolumn{3}{|c|}{ Shapiro-Wilk } \\
\hline & & Statistic & df & Sig. & Statistic & $\mathrm{df}$ & Sig. \\
\hline \multirow[t]{2}{*}{ Nilai } & Eksperimen &, 183 & 18 &, 114 &, 873 & 18 &, 020 \\
\hline & Kontrol & 126 & 22 & $200^{*}$ & ,928 & 22 &, 111 \\
\hline
\end{tabular}


Dapat dinyatakan bahwa nilai signifikansi kelas eksperimen yaitu sebesar 0,114 dan kelas control 0,200. Kedua dari nilai signifikasinsi tersebut lebih besar dari taraf nyata 0.05 dengan kata lain dapat disimpulkan bahwa data hasil tes kemampuan pemecahan masalah matematik berasal dari populasi yang berdistribusi normal.

\section{Uji Homogenitas}

Dalam penelitian ini uji homogenitas dilakukan denganteknik uji bartlet dengan menggunakan bantuan SPSS. Hasil uji homogenitas terangkum pada tabel berikut:

Hasil Uji Homogenitas Varians Test

Kemampuan Pemecahan Masalah Matematik

\section{Test of Homogeneity of Variances}

\begin{tabular}{|l|l|r|r|r|r|}
\hline \multicolumn{1}{|l|}{$\begin{array}{l}\text { Residual for } \\
\text { Nilai }\end{array}$} & $\begin{array}{c}\text { Levene } \\
\text { Statistic }\end{array}$ & df1 & df2 & \multicolumn{1}{c|}{ Sig. } \\
\cline { 2 - 6 } & Based on Mean & 1,221 & 1 & 38 &, 276 \\
\hline & Based on Median & 1,008 & 1 & 38 &, 322 \\
\cline { 2 - 7 } & $\begin{array}{l}\text { Based on Median and with } \\
\text { adjusted df }\end{array}$ & 1,008 & 1 & 37,997 &, 322 \\
\cline { 2 - 7 } & Based on trimmed mean & 1,377 & 1 & 38 &, 248 \\
\hline
\end{tabular}

Dapat dinyatakan bahwa nilai signifikansi dalam pegujian homogenitas yaitu sebesar 0,276. Nilai tersebut lebih besar dari taraf kepercayaan 0.05. dengan demikian dapat disimpulkan bahwa data penelitian bersifat homogen.

\section{Pengujian Hipotesi}

Pengujian hipotesis yang dilakukan dalam penleitian ini yaitu uji kesamaan rata-rata dan two way anova. Hasil pengujian hipotesis serta interpretasinya disajikan dalam beberapa rangakain sebagai berikut.

Rangkuman Analisi Varian Dua Jalur

\section{Tests of Between-Subjects Effects}

\begin{tabular}{|l|r|r|r|r|r|}
\hline Dependent Variable: & $\begin{array}{l}\text { Nilai } \\
\text { Sype III } \\
\text { Sum of } \\
\text { Squares }\end{array}$ & Df & Mean Square & F & Sig. \\
\hline $\begin{array}{l}\text { Corrected } \\
\text { Model }\end{array}$ & $2205,856^{\mathrm{a}}$ & 5 & 441,171 & 43,972 &, 000 \\
\hline Intercept & 225819,113 & 1 & 225819,113 & 22507,831 &, 000 \\
\hline Kategori & 135,392 & 2 & 67,696 & 6,747 &, 003 \\
\hline Kelas & 296,081 & 1 & 296,081 & 29,511 &, 000 \\
\hline $\begin{array}{l}\text { Kategori } * \\
\text { Kelas }\end{array}$ & 1629,356 & 2 & 814,678 & 81,201 &, 000 \\
\hline Error & 341,119 & 34 & 10,033 & & \\
\hline Total & 234957,000 & 40 & & & \\
\hline Corrected Total & 2546,975 & 39 & & & \\
\hline a. R Squared =,866 (Adjusted R Squared = ,846) & & & \\
\hline
\end{tabular}


Berdasarkan hasil analisis ANOVA dua jalur pada tabel 4,6 dengan taraf signifikansi 0.05 diperoleh bahwa :

a) Berdasakan hasil ANOVA dua jalur pada baris metode diperoleh nilai signifikansi sebesar $0.000<0.05$. hal ini berarti terdapat perbedaan kemampuan matematik yang signifikan antara siswa yang memperoleh pembelajaran matematik dengan menggunakan media pembelajaran permainan ular tangga dengan pembelajaran ekspositori. Dengan kata lain terdapat perbedaan kemampuan pemecahan masalah matemtik antara siswa yang diajar menggunakan media permainan ular tangga dan siswa yang diajar menggunakan pembelajaran ekspositori.

b) Pada baris motivasi diperoleh nilai signifikansi sebesar $0.003<0.05$, artinya terdapat perbadaan kemampuan pemecahan masalah matematik berdasarkan katergori motivasi belajar tinggi, sedang dan rendah

c) Pada baris kategori *Kelas diperoleh nilai dignifikansi sebesar 0.000 , secara statistik dapat dinyatakan terdapat pengaruh interaksi yang signifikan antara pendekatan pembelajaran dan motivasi belajar terhadap kemampuan pemecahan masalah matematik.

Uji lanjutan dalam penelitian ini menggunakan teknik uji Tuckey. Hasil uji Tuckey dapat dilihat pada tabel berikut :

Rangkuman Hasil Uji Tuckey

\section{Multiple Comparisons}

Dependent Variable: Nilai

Tukey HSD

(I) Interaksi

(J) Interaksi

Mean

Difference

(I-J)

\begin{tabular}{l|l} 
Eksperimen & Eks \\
tinggi & sed
\end{tabular}

tinggi

(n)

Eksperimen

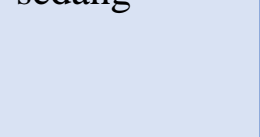

Eksperimen rendah

Differen $(\mathrm{I}-\mathrm{J})$

$9,70^{*}$

Eksperime

rendah

Kontrol tinggi

Kontrol sedang

Kontrol rendah

$17,12^{*}$

Eksperimen

$14,62^{*}$

$14,90^{*}$

4,12

$-9,70^{*}$

tinggi

Eksperimen

rendah

Kontrol tinggi

7,43

Kontrol sedang

4,93

Kontrol rendah

5,21

$-5,57$

$-17,12^{*}$ sedang

\begin{tabular}{l|l} 
Eksperimen \\
sedang
\end{tabular}

Std.

Error

Sig.

95\% Confidence Interval

\begin{tabular}{l|l} 
Lower & Upper \\
Bound & Bound
\end{tabular}

2,772

1,33

18,06

3,054

, 015

\begin{tabular}{|l|l|}
\hline $7,91 \quad 26,34$ \\
\hline
\end{tabular}

, 000

2,893 ,000

2,603

,000

5,89

23,36

3,054

, 755

7,05

22,76

2,772

, 015

$-5,09$

13,34

3,137

,196

$-18,06$

$-1,33$

2,980

,570

$-2,04$

16,90

2,700

$-4,07$

13,92

3,137

,403

$-2,94$

13,35

tinggi

Eksperimen

3,054

,494

$-15,04$

3,90

sedang

\begin{tabular}{|l|r|r|r|r|r|}
\hline Kodang & $-2,50$ & 3,244 &, 971 & $-12,29$ & 7,29 \\
\hline Kontrol tinggi & $-2,22$ & 2,988 &, 975 & $-11,24$ & 6,80 \\
\hline Kontrol sedang & $-13,00^{*}$ & 3,388 &, 006 & $-23,23$ & $-2,77$ \\
\hline
\end{tabular}

LPPM Universitas Jambi

Halaman | 909 


\begin{tabular}{|c|c|c|c|c|c|c|}
\hline \multirow[t]{5}{*}{$\begin{array}{l}\text { Kontrol } \\
\text { tinggi }\end{array}$} & $\begin{array}{l}\text { Eksperimen } \\
\text { tinggi }\end{array}$ & $-14,62^{*}$ & 2,893 &, 000 & $-23,36$ & $-5,89$ \\
\hline & $\begin{array}{l}\text { Eksperimen } \\
\text { sedang }\end{array}$ & $-4,93$ & 2,980 &, 570 & $-13,92$ & 4,07 \\
\hline & $\begin{array}{l}\text { Eksperimen } \\
\text { rendah }\end{array}$ & 2,50 & 3,244 & ,971 & $-7,29$ & 12,29 \\
\hline & Kontrol sedang & ,28 & 2,823 & 1,000 & $-8,24$ & 8,80 \\
\hline & Kontrol rendah & $-10,50^{*}$ & 3,244 &, 030 & $-20,29$ &,- 71 \\
\hline \multirow[t]{5}{*}{$\begin{array}{l}\text { Kontrol } \\
\text { sedang }\end{array}$} & $\begin{array}{l}\text { Eksperimen } \\
\text { tinggi }\end{array}$ & $-14,90^{*}$ & 2,603 &, 000 & $-22,76$ & $-7,05$ \\
\hline & $\begin{array}{l}\text { Eksperimen } \\
\text { sedang }\end{array}$ & $-5,21$ & 2,700 & ,403 & $-13,35$ & 2,94 \\
\hline & $\begin{array}{l}\text { Eksperimen } \\
\text { rendah }\end{array}$ & 2,22 & 2,988 & ,975 & $-6,80$ & 11,24 \\
\hline & Kontrol tinggi &,- 28 & 2,823 & 1,000 & $-8,80$ & 8,24 \\
\hline & Kontrol rendah & $-10,78^{*}$ & 2,988 &, 012 & $-19,80$ & $-1,76$ \\
\hline \multirow[t]{5}{*}{$\begin{array}{l}\text { Kontrol } \\
\text { rendah }\end{array}$} & $\begin{array}{l}\text { Eksperimen } \\
\text { tinggi }\end{array}$ & $-4,12$ & 3,054 &, 755 & $-13,34$ & 5,09 \\
\hline & $\begin{array}{l}\text { Eksperimen } \\
\text { sedang }\end{array}$ & 5,57 & 3,137 & ,494 & $-3,90$ & 15,04 \\
\hline & $\begin{array}{l}\text { Eksperimen } \\
\text { rendah }\end{array}$ & $13,00^{*}$ & 3,388 & ,006 & 2,77 & 23,23 \\
\hline & Kontrol tinggi & $10,50^{*}$ & 3,244 & ,030 &, 71 & 20,29 \\
\hline & Kontrol sedang & $10,78^{*}$ & 2,988 & ,012 & 1,76 & 19,80 \\
\hline \multicolumn{7}{|c|}{$\begin{array}{l}\text { Based on observed means. } \\
\text { The error term is Mean Square(Error) }=28,695 \text {. }\end{array}$} \\
\hline
\end{tabular}

Berdasarakan uji komparasi antar kolom, dengan taraf signifikansi 0.05 diperoleh bahwa:

a. Motivasi tinggi yang diajar menggunakan media permainan ular tangga (i) dan kategori motivasi tinggi yang diajar dengan pembelajaran ekspositori (j) memperoleh nilai signifikansi sebesar 0.000 artinya terdapat perbedaan yang sinifikan. jika dilihat dari selisih rataannya yaitu sebesar 14,62 dan merupakan bilangan positif maka dapat dinyatakan bahwa kemampuan pemecahan masalah matematik siswa dengan motivasi tinggi yang menggunakan media pembelajaran permainan ular tangga lebih baik dari pada siswa dengan memperoleh pembelajaran secara ekspositori.

b. Motivasi sedang yang diajar menggunakan media permainan ular tangga (i) dan kategori motivasi sedang yang diajar dengan pembelajaran ekspositori (j) memperoleh nilai signifikansi sebesar 0.403 artinya tidak terdapat perbedaan yang sinifikan. Namun jika dilihat dari selisih rataannya yaitu sebesar 5,21 dan merupakan bilangan positif maka dapat dinyatakan bahwa kemampuan pemecahan masalah matematik siswa dengan motivasi sedang yang menggunakan media pembelajaran permainan ular tangga lebih baik dari pada siswa dengan memperoleh pembelajaran secara ekspositori.

c. Motivasi rendah yang diajar menggunakan media permainan ular tangga (i) dan kategori motivasi rendah yang diajar dengan pembelajaran ekspositori (j) memperoleh nilai signifikansi sebesar 0.006 artinya tidak terdapat perbedaan yang sinifikan. Namun jika dilihat dari selisih rataannya yaitu sebesar 13,00 dan merupakan bilangan positif maka dapat dinyatakan bahwa kemampuan pemecahan masalah matematik siswa dengan 
motivasi rendah yang menggunakan media pembelajaran permainan ular tangga tidak lebih baik dari pada siswa dengan memperoleh pembelajaran secara ekspositori.

\section{KESIMPULAN DAN SARAN}

Berdasarkan hasil penelitian dan pembahasan maka dapat ditarik beberapa kesimpulan penelitian sebagai berikut : Kemampuan pemecahan masalah matematik siswa yang menggunakan media pembelajaran permainan ular tangga berbasis budaya Banten lebih unggul dari pada kemampuan pemecahan masalah matematik siswa yang menggunakan pembelajaran ekspositori, Terdapat pengaruh interaksi antara pembelajaran dan motivasi belajar terhadap kemampuan pemecahan masalah matematik siswa SD kelas IV.

Beberapa saran sebagai berikut Bagi Siswa : diharapkan terlibat aktif dalam mengikuti pembelajaran di kelas dan di luar kelas sehingga dapat memahai materi yang diajarakan dan memperoleh hasil belajar yang optimal sesuai dengan perencanaan yang telah dibuat, Bagi Guru : diharapkan memperhatikan media pembelajaran yang digunakan pada setiap proses pembelajaran serta motivasi belajar siswa agar tepat dalam merancang pembelajaran sehingga mampu meningkatkan kemampuan pemecahan masalah matemtik siswa, Bagi Penliti Lain : diharapkan mampu memperdalam dan memperluas lingkup penelitian, sehingga dapat memberikan dampak serta kontribusi yang lebih besar bagi dunia pendidikan.

\section{DAFTAR PUSTAKA}

Arifin, Z. (2015). Evaluasi Pembelajaran Penulis. In Direktorat Jenderal Pendidikan Islam Kementerian Agama RI.

Basuki Wibawa, Mahdiyah, Jarnawi Afgani (2019). Metode Penelitian Pendidikan. Tangerang Selatan : Universitas Terbuka, 8.4-8.21

Danoebroto, Sri Wulandari (2013). Model Pembelajaran Matematika Berbasis Pendidikan Multikultural. Jurnal Pembangunan Pendidikan: Fondasi dan Aplikasi, 1.

Monika, M., \& Adman, A. (2017). Peran Efikasi Diri Dan Motivasi Belajar Dalam Meningkatkan Hasil Belajar Siswa Sekolah Menengah Kejuruan. Jurnal Pendidikan Manajemen Perkantoran, 2(2), 109. https://doi.org/10.17509/jpm.v2i2.8111

Muhammad Daud Siagian (2016). Kemampuan Koneksi Matematika Dalam Pembelajaran Matematika. MES (Journal of Mathematics Education and Science), 2, 58-67

Normina. (2017). Pendidikan dalam kebudayaan. Ittihad Jurnal Kopertais Wilayah XI Kalimantan, 15(28), 17-28.

Pendidikan, M., Setia, P., Pendidikan, D., \& Umum, M. (2004). Daftar pustaka. 11(1), 20022004.

Rina Devianty. (2017). Bahasa Sebagai Cermin Kebudayaan. Jurnal Tarbiyah, 24(2), 226245.

Salam, N., Safei, \& Jamilah. (2019). Pengembangan Media Pembelajaran Ular Tangga Pada Materi Sistem Saraf. Al-Ahya, 1(pengembangan media pembelajaran ular tangga pada materi sistem saraf), 18.

Siregar, N. F. (2018). Komunikasi Matematis Dalam Pembelajaran Matematika. Logaritma: $\begin{array}{lllll}\text { Jurnal Ilmu-Ilmu Pendidikan Dan } & \text { Sains, }\end{array}$ https://doi.org/10.24952/logaritma.v6i02.1275

Sri Anitah, dkk (2014). Strategi Pembelajaran di SD. Tangerang Selatan : Universitas Terbuka, 6.3

Sukaenah, Q., \& Yuliana, R. (2019). Pengembangan Modul Budaya Berbasis Kearifan Lokal Banten Pada Mata Pelajaran Ips. 2(1), 298-309. 
Supriadi, Arisetyawan, Andika Tiurlina (2016). Mengintegrasikan Pembelajaran Matematika Berbasis Budaya Banten Pada Pendirian Sd Laboratorium Upi Kampus Serang. Mimbar Sekolah Dasar, 3(1), 1-18.

Suprihatin, S. (2015). Upaya Guru Dalam Meningkatkan Motivasi Belajar Siswa. PROMOSI (Jurnal Pendidikan Ekonomi), 3(1), 73-82. https://doi.org/10.24127/ja.v3i1.144 